\title{
PREPARATION AND TENSILE CHARACTERIZATION OF JUTE BASED BIO COMPOSITES
}

\author{
Mahammad Sharif Budihal ${ }^{1}$ \\ ${ }^{1}$ Assistant Professor, Mechanical Engineering Department, A.I.T.M., Bhatkal
}

\begin{abstract}
In recent days the natural fibers of renewable natural resources have the ability to behave as a reinforcing material for polymer composites, instead of using the carbon and other artificial fibers in all this jute is commonly used natural fiber because of its merits like it is easily available less density less production cost with good mechanical properties. to this composite material the mechanical attributes depends on various factors like fiber length, quantity, etc in this research work attempts has made to investigate experimentally the impact of jute fiber glass fibre carbon fibre and epoxy resin on the tensile properties of composites at different temperatures and to determine the tensile properties jute based epoxy bio composites at different temperatures, composite consist of two materials in that first material is known as the reinforcing phase. It is of fibres sheets or particles form and it is mixed with another material known as matrix phase. It is noted that natural fibre composites are eco-friendly as compared to glass fibre composites and also shows that the jute fibre introduced the resin matrix as reinforcement it optimizes the mechanical properties.
\end{abstract}

Keywords: Fibres, Renioforcement, Bio composites, Matrix

\section{INTRODUCTION}

To produce 'green' products ecological concerns have initiated substantially interest in natural materials. Increasing crude oil prices of the raw material of synthetic fibre and high processing cost initiate the development concepts of sustainability and reconsideration of renewable resources because of the quick increasing environmental awareness, and increasing global waste problems.In automotive parts Natural fibre will find many applications as reinforcing material.

Natural fibre can be used in automotive applications, construction as well as in packaging industries with few drawbacks. in thermo set and thermoplastic matrices form. The conventional inorganic fibre in polymer matrix composites being replaced by natural fibres the use of natural fibrer is increasing very rapidly in recent days. Natural fiber-reinforced thermoplastics have the ability to replace the wood-based material in many applications. in the future natural fibre have more biodegradability, light weight, low cost, compared to glass and carbon fibre, leads to development of green material. , in recent years, natural fibres have attracted more and more interest as reinforcements for both thermoplastic and thermosetting polymer composites. Because Nowadays, the increasing environmental awareness around now more focus is to produce green materials some specific properties of Natural fibre enhances to replace it with glass and carbon fibre.

Bio-composites obtained from natural fibre and thermoplastics and thermo sets can maintain the balance between economy and environment due to this they can be used in the fields of aerospace, defence, marine, sporting goods, These materials exhibit good durability, design flexibility and lightweight. Due to some desired properties of bio-composites they can be used for many special purpose applications.

In the present chapter we will mainly concentrate on the structure, properties and recyclability of commonly used natural fiber reinforced polymer composites. With the structures of other natural fibre.

\subsection{Significance of Proposed Project}

Several researchers have carried out extensive experimental investigations on various properties of composites such as strength, hardness, toughness, density of fiber reinforced composites. As reinforcing natural fibre yields environmental benefits with respect to disposability and utilization of raw material. It possesses good electrical resistance, resistance to fracture, low density, bio degradability and environmental friendly. It was reported that combination of natural fiber and polymer resin has great synergy. The volume fraction of reinforcement has also significant effect on hardness of natural fiber composites. In the present work, an attempt has made to prepare Jute Epoxy reinforced polymer composites, glass Epoxy reinforced polymer composites, carbon and jute Epoxy reinforced polymer composites to study the tensile properties at different temperatures.

\subsection{Problem Statement}

Preparation and experimental study on tensile properties of the Jute based bio composites at different temperatures. 


\subsubsection{Objectives of the Project Work}

- Preparation of bio-composites by using carbon fiber and short Jute fibeer, glass fibęr, in Epoxy ręsin matrix.

- To study experimentally the effect of Jute fiberr, glass fiberer, carbon fiber and Epoxy reesin on the tensile properties of composites at different temperatures.

- To determine tensile properties of Jute based Epoxy bio composites at different temperatures $\left(0^{\circ}\right.$, $27^{\circ} \mathrm{C} ., 50^{\circ} \mathrm{C}, 80^{\circ} \mathrm{C}, 110^{\circ} \mathrm{C}$ ).

- To analyze and interpret the results.

\subsection{Scope of the proposed project work}

This project is limited preparation of jute based bio composites using short jute fibre, glass fibre, and carbon fibre as reinforcements in epoxy resin and to study experimentally the effect of Jute fibre, glass fibre, carbon fibre and Epoxy ressin on the tensile properties of composites at different temperatures $\left(0^{\circ}\right.$, $\left.27^{\circ} \mathrm{C} ., 50^{\circ} \mathrm{C}, 80^{\circ} \mathrm{C}, 110^{\circ} \mathrm{C}\right)$

\section{FABRICATION AND TESTING}

This chapter describes the preparation and fabrication of specimens according to the American Standards for Testing Materials (ASTM).

The present study involves the evaluation of the Tensile properties of the new class of composite i.e., Short Jute fibre, glass fibre, and carbon fibre rẹinforced with Epoxy rẹsin with Adhesive agent at different temperatures.

The following methods are adopted for various activities

1. Fabrication by Hot Compression molding technique.

2. Tests for mechanical characterization

3. Tensile test

\subsection{Fabrication by Hot Compression Molding}

\section{Technique}

- First chopped jute fibre, Glass fibre, carbon fibre and pre weighed amount of resin are mixed and water is added to the mixture of chopped jute fibre and resins here water act as binder which hold chopped jute fibre and resin firmly .talc and Calcium carbonate are added as fillers

- Wait until full water is absorbed

- Layers of chopped jute fibre and resin are formed one over the other like sandwich model

- This sandwich model is compressed in cold compression molding machine to prepare biocomposite

- After bio composite removed from compression molding machine instant cooling is done through blower or any other means

- Then bio composite covered by Teflon for uniform distribution of heat

- Then keep the composite for some time and finally cut the specimen in to required sizes.

\subsubsection{Materials used for Fabrication}

The materials used in preparation of composite specimens are mentioned in detail below.

\section{For BJE Series}

- $\quad$ Matrix used: Epoxy resin(A-331), with $10 \%$ talc and 5 $\%$ Calcium Carbonate

- Reinforcement: Short Jute fibre(1mm-2mm)

- Hardener: A-062 (100ml per kg of resin)

\section{For FGJ Series}

- Matrix used: Matrix - epoxy, with 7\% talc and $3 \%$ Clay

- Reinforcement: Short Jute fibre(1mm-2mm),glass fibre and carbon fibre

- Hardener: A-062 (100ml per kg of resin)

\section{For FGE Series}

- Matrix used: Matrix - epoxy, with $10 \%$ talc and $5 \%$ filler

- Reinforcement: Short glass fibre (1mm-2mm)

- Hardener: A-062 (100ml per kg of resin)

\subsection{Piercing of Laminated into Desired Size}

- To cut each laminate into required size a wire hacksaw blade is used

- Dog bone shape for tensile test according to ASTMD368 standard.

Table 1: Chęmical structure of Jutę fibre:

\begin{tabular}{|l|l|}
\hline Constituent & Percentage \\
\hline Cẹllulose & $65 \%$ \\
\hline Hęmi-cellulose & $22 \%$ \\
\hline Lignin & $11 \%$ \\
\hline Watęr soluble & $1.5 \%$ \\
\hline
\end{tabular}

\subsubsection{Chemical Composition of Glass Fibre}

Glass composed of $\mathrm{SiO}_{2} 54 \%$ in weight, $\mathrm{Al}_{2} \mathrm{O}_{3} 14 \%$ in weight, $\mathrm{CaO}+\mathrm{MgO} 22 \%$ in weight, $\mathrm{B}_{2} \mathrm{O}_{3} 10 \%$ in weight and $\mathrm{Na}_{2} \mathrm{O}+\mathrm{K}_{2} \mathrm{O}$ less than $2 \%$ in weight. And Some other materials present in the form of impurity levels.

\section{TESTS FOR MECHANICAL CHARACTERIZATION}

\subsection{Tensile Test}

The tensile test has to be carried out according to ASTM D638 standards, which includes the tensile properties of reinforced in Dumbbell shaped test specimens is tested under normal working conditions and testing machine rpm.

\subsubsection{Experimental Setup}

A tensile testing machine is used to conduct the tension test under different loading conditions. The load cell of $10 \mathrm{kn}$ is 
used to measure and apply the load on the composite specimen the load is applied uniformly at the rate of $10 \mathrm{~mm} / \mathrm{min}$ and respective displacement of the sample which is in touch with the specimen are noted down. The tensile testing machine is shown in the figure

\subsubsection{Test Specimen}

According to ASTM 638 composite specimens were prepared for test as shown in figure, the dimensions of the specimen are shown in the table below.

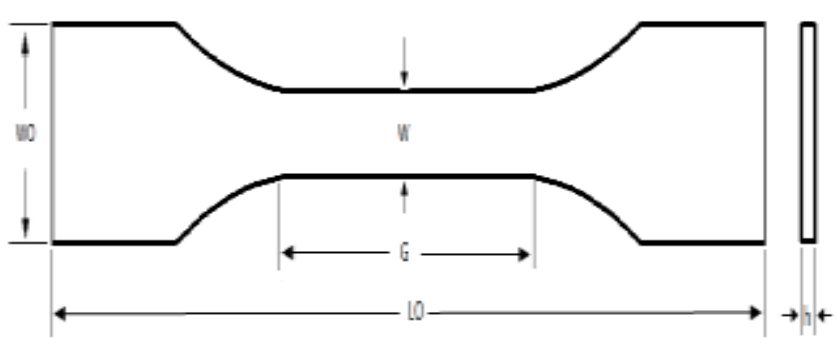

Fig 1: Tensile test specimen

Table 2: size of the tensile test specimen

\begin{tabular}{|l|l|}
\hline Particulars & Size in $\mathbf{~ m m}$ \\
\hline $\begin{array}{l}\text { Overall } \\
\text { length(LO) }\end{array}$ & 170 \\
\hline $\begin{array}{l}\text { Overall } \\
\text { width(WO) }\end{array}$ & 22 \\
\hline Gauge length $(\mathrm{G})$ & 50 \\
\hline $\begin{array}{l}\text { Width of narrow } \\
\text { section }(\mathrm{W})\end{array}$ & 16 \\
\hline
\end{tabular}

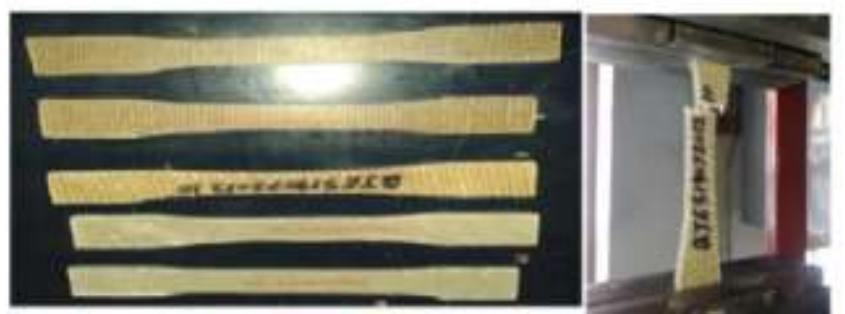

Fig 2: Specimens before and after tensile test

\subsection{Procedure}

The test specimen is placed in-between the two jaws of the machine, The constant load of $100 \mathrm{~mm} / \mathrm{min}$ is applied on the specimen. The specimen of $50 \mathrm{~mm}$ gauge length, $25 \mathrm{~mm}$ wide and $10 \mathrm{~mm}$ thickness is used.

The specimen is fixed in the tensile machine jaws and initial adjustments are made. Then the machine is put on start and load will be applied uniformly on the specimen. The values of load and corresponding deflection are noted. From the obtained values strain Young's modulus and stress, are to be evaluated using the suitable formulae. Then the graph of stress Vs strain is plotted. The obtained values of Young's modulus are depend on the slope of linear portion of the stress-strain curve.Totally 30 samples were tested at different temperatures and the results are given in the table

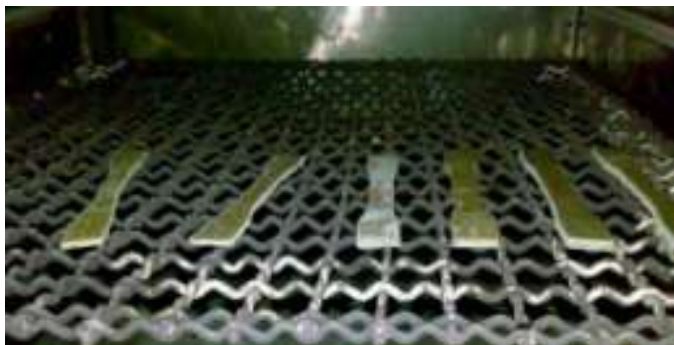

Fig 3: Specimens kept in oven for heat treatment

\section{EXPERIMENTAL RESULTS}

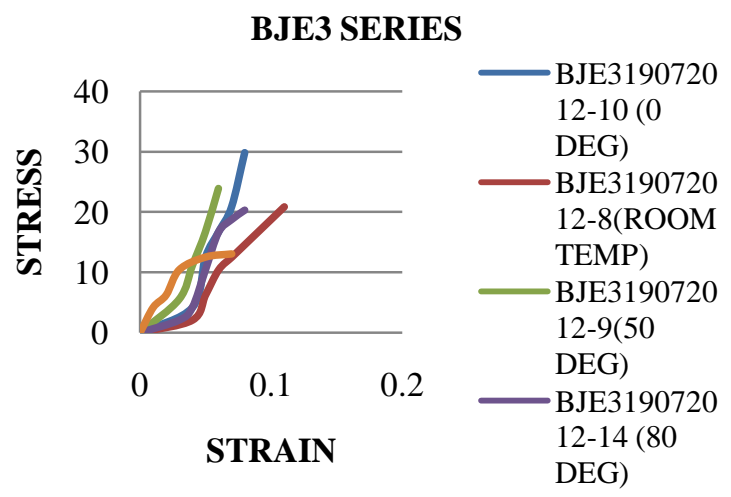

Fig 4: stress vs strain for BJE3 series

\section{BJE5 SERIES}

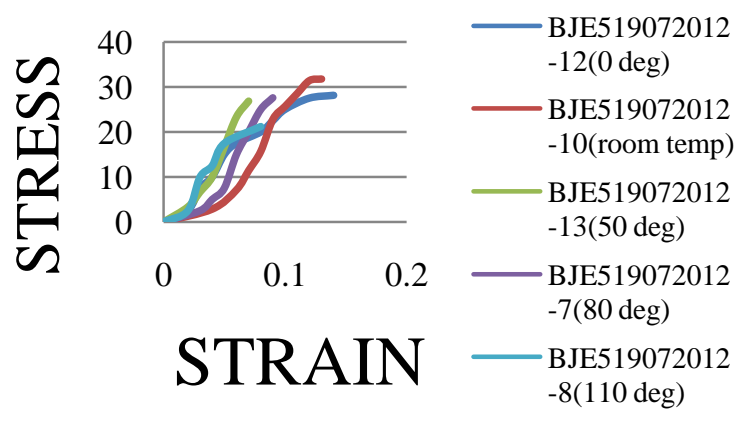

Fig 5: stress vs strain for BJE5 series

\section{FGE 3mm SERIES}

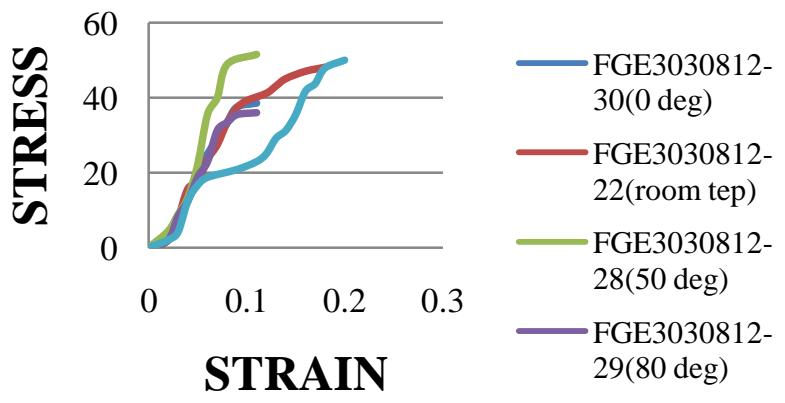

Fig 6: stress vs strain for FGE 3mm series 


\section{FGJ5 SERIES}

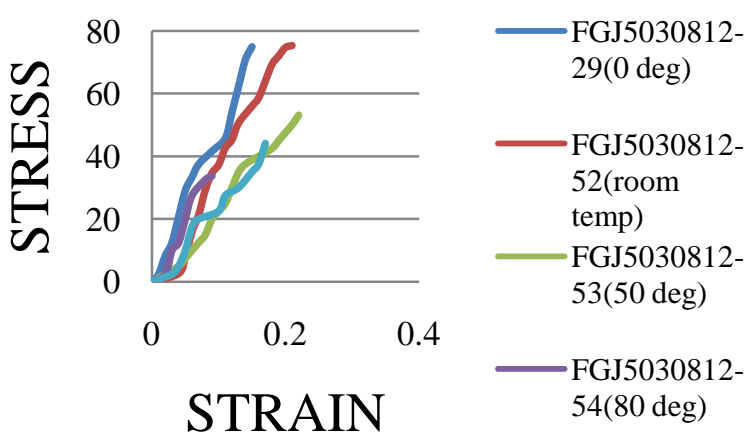

Fig 7: stress vs strain for FGJ5 series

\section{FGE5 SERIES}

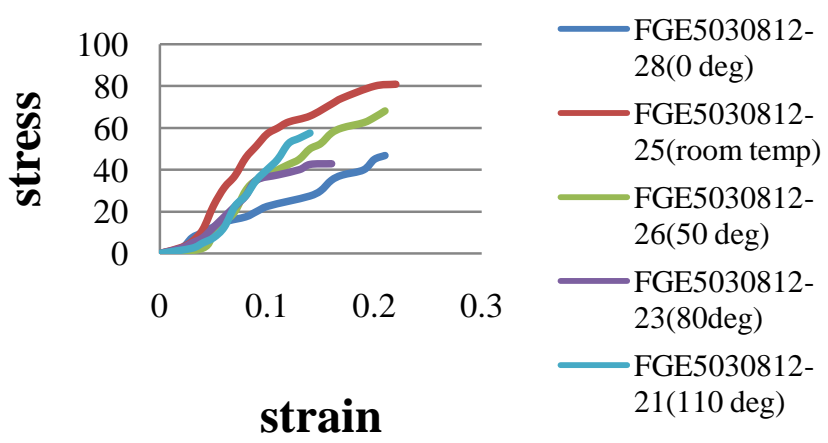

Fig 8: stress vs strain for FGE5 series

\section{FGJ SERIES(3mm)}

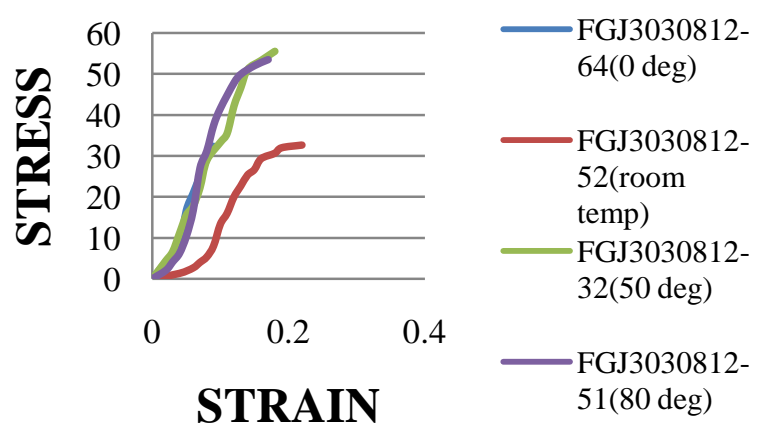

Fig 9: stress vs strain for FGJ 3mm series

\section{CONCLUSION}

- Hot compression molding method is effectively employed for the preparation of jute based biocomposites using glass fibre and carbon fibre

- From above results it is clear that all above specimens are brittle in nature.

- Natural fibre composites are more eco-friendly as compared to the glass fibre composites in most cases due to the following reasons:
- Natural fibre production has less environmental problems as compared to glass fibre production

- Natural fibre composites have more fibre content for the same performance

- For BJE series optimum properties are obtained in case temperature of $800 \mathrm{C}$ among different heating conditions. $1100 \mathrm{C}$ indicated a loss of strength, strain to fracture. This may be due to larger cross linkage of fibre at $1100 \mathrm{C}$ condition resulting loss of ductility of the matrix. At 500C composites exhibits fibre pull out.

- At higher temperatures the thermal degradation of fibre would occur, leading to the decrease of tensile properties

- $\square$ Specimens at $80 \mathrm{C}$ exhibited better performance upon heat treatment. This further proves the superiority of $800 \mathrm{C}$ over $500 \mathrm{C}$ and $1100 \mathrm{C}$ temperature conditions.

- For FGE series at temperatures from 0 to $50^{\circ} \mathrm{Cthe}$ tensile strength is seems to be stable, which indicates the mechanical behavior of GFRP composites remains almost same this temperature range and after this range as temperature decreases tensile strength increases

- This phenomenon is due to the more stiffness of the amorphous polymer matrix because of low temperatures. Further, if the material contain a high level of moisture, then the volume expansion of the water during the freezing could cause the beginning of micro cracks and lowers the mechanical properties

- At high temperatures, near and above $100^{\circ} \mathrm{C}$ flexural modulus and, the mechanical strength reduces due to the change of state in the polymer

- Mechanical properties of glass fibre reinforced composites increased when the temperature decreased.

- After comparing the mechanical properties of jute reinforced and glass reinforce composites, the results shows that the jute fibre when added into the resin matrix as reinforcement, improve the mechanical properties, but the improvement is less than that obtained by introduction of glass and other high performance fibre. Hence, the jute fibre can be used as reinforcement where modest strength and modulus are required. Another use for the jute fibre is that, it can be used as a "filler" fibre, replacing the glass as well as the resin in a filament wound component.

\section{REFERENCES}

[1] Jartiz, A.E., Design 1965, p.18.

[2] Kelly, A. Sci. American 217, (B), (1967): p. 161.

[3] Berghezan,A.Nucleus,8(5),1966, (Nucleus Editeur,1,rhe,Chalgrin,Paris, 16(e).

[4] Suchetclan Van, Philips Res. Repts. Volume 27, (1972): p. 28

[5] Yan Li , Chunjing $\mathrm{Hu}$, Yehong Yu "Interfacial studies of sisal fibre reinforced high density polyethylene (HDPE) composites" Part A 39 (2008) 570-578

[6] S.V. Joshi, L.T. Drzal, A.K. Mohanty, S. Arora "The mechanical properties of vinyl ester resin matrix composites reinforced with alkali-treated jute fibres" Part A 32 (2001) 119-127. 
[7] K. RANA, A. MANDAL, B.C. MITRA, R. JACOBSON, R. ROWELL, A. N. BANERJEE "Short Jute Fibre-Reinforced Polypropylene Composites: Effect of Compatibilizer" Journal of Applied Polymer Science, Vol. 69, 329-338 (1998).

[8] N. Shah and S. C. Lakkad," Mechanical Properties Of Jute-Reinforced Plastics, Fibre Science and Technology "15 (1981) 4146.

[9] D. Ray, B.K. Sarkara, A.K. Rana, N.R. Bose "The mechanical properties of vinylester resin matrix composites reinforced with alkali-treated jute fibres" Part A 32 (2001) 119-127

[10] Prosenjit Saha, Suvendu Manna, Sougata Roy Chowdhury, Ramkrishna Sen, Debasis Roy, Basudam Adhikari "Enhancement of tensile strength of lignocellulosic jute fibre by alkali-steam treatment" 101 (2010) 3182-3187

[11] Jochen Gassan, Andrzej K. Bledzki, Possibilities for improving the mechanical properties of jute/epoxy composites by alkali treatment of fibres, Composites Science and Technology 59 (1999) 1303-1309.

[12] Monteiro S.N.; Rodriquez R.J.S.; De Souza M.V., D'Almeida J.R.M., "Sugar Cane Bagasse Waste as Reinforcement in Low Cost Composites", Advanced performance Material, Volume 5, No.3, (December 1998): p. 183-191. 